\title{
50. Festtagung des Vereins
}

\section{Rheinisch-westfälischer Augenärzte am 21. u. 22. Mai in Bonn}

Zur Feier seiner 50. Sitzung - da wegen der Ruhrbesetzung das 25jährige Bestehen nicht festlich begangen werden konnte - hatte der Verein seine Mitglieder mit ihren Damen nach Bonn geladen und die Erschienenen schon am Vorabend zu festlichem Auftakt versammelt.

Den eigentlichen Festakt eröffnete der Vorsitzende Plange-Münste $\tau$ mit einem Überblick über die Geschichte des Vereins, besonders seiner Gründung und der bisher geleisteten Arbeit, die der Förderung der Wissenschaft, der Vertretung der Standes- und wirtschaftlichen Inter-essen und des kollegialen Verkehrs gewidmet war. Reiche Arbeit an Vorträgen, Referaten,

Fortbildungskursen ist geleistet worden und soil in gleicher Weise auch in Zukunft fortgesetzt werden. Nach herz-erquickenden und erhebenden Begrüßungsworten von Römer-üonn als Vertreter der rheinischen Universitäten hielt A xenfeld-Freïbuvg einen in Form und Inhalt wahrhaften Festvortrag über, ,Infektion und Disposition in der Augenheilkunde”. Der einmütige Beifall derVersamm-lung kam in der Ernennung des Vortragenden zum Ehrenmitglied des Vereins zu besonderem Ausdruck.

E. Ein Festmahl krönte den offiziellen Teil. Der Nachmittag führtedie Festversammlung nach Königswinter und hielt die Mitglieder mithren Damen noch lange gemütlich zusammen. Heßberg (Essen). 